\title{
Aortic clamping strategy and postoperative stroke
}

\author{
Mohamad Alaeddine, MD, ${ }^{\mathrm{a}}$ Vinay Badhwar, MD, ${ }^{\mathrm{b}}$ Maria V. Grau-Sepulveda, MD, \\ Lawrence M. Wei, MD, ${ }^{b}$ Chris C. Cook, MD, ${ }^{b}$ Michael E. Halkos, MD, ${ }^{\mathrm{d}}$ Vinod H. Thourani, MD, \\ Jeffrey P. Jacobs, MD, ${ }^{f}$ Roland Matsouaka, PhD, ${ }^{\mathrm{c}}$ James Meza, MD, ${ }^{\mathrm{c}}$ Matthew Brennan, MD, \\ Thomas G. Gleason, MD, ${ }^{\mathrm{a}}$ and Danny Chu, MD, FACS ${ }^{\mathrm{a}}$
}

\section{ABSTRACT}

Objective: The effect of aortic clamping strategy on short-term stroke during proximal graft construction for coronary artery bypass grafting $(\mathrm{CABG})$ remains undefined. The aim of this study was to test the hypothesis that partial occluding clamp (POC) technique does not increase incidence of postoperative stroke compared with single clamp (SC) technique for performing proximal coronary anastomoses.

Methods: We identified 52,611 patients who underwent on-pump CABG in the Society of Thoracic Surgeons Adult Cardiac Surgery Database from July 1, 2014 to March 31, 2015. Propensity scores for POC were calculated on the basis of validated Society of Thoracic Surgeons predicted risk of postoperative stroke scores and used to adjust for intergroup differences to derive 17,819 matched pairs for analysis.

Results: Despite a similar number of total bypass grafts between matched SC versus POC groups, myocardial ischemic times were shorter $(74.1 \pm 29.2$ minutes vs $57.0 \pm 23.3$ minutes; $P<.0001)$ as were cardiopulmonary bypass times $(95.0 \pm 35.0$ minutes vs $89.7 \pm 34.4$ minutes; $P<.0001)$ for the POC group. Postoperative stroke rates were similar between SC versus POC $(0.9 \%$ vs $1.1 \%$; risk ratio, $1.1 ; 95 \%$ confidence interval, $0.9-1.4 ; P=.3$ ) as were mortality rates $(1.3 \%$ vs $1.3 \%$; risk ratio, $1.0 ; 95 \%$ confidence interval, $0.8-1.2 ; P=.9)$.

Conclusions: Aortic clamping strategy for constructing proximal anastomoses in $\mathrm{CABG}$ procedures does not affect short-term incidence of postoperative stroke or mortality. The use of POC incurred shorter myocardial ischemic and perfusion times compared with the SC technique with similar total number of bypass grafts.

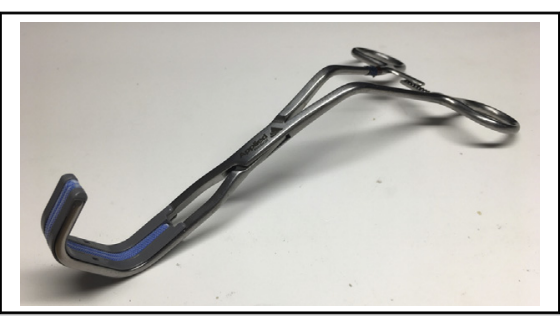

Partial occluding clamp used for constructing proximal coronary anastomosis.

Central Message

No differences in early postoperative stroke rates regardless of proximal coronary anastomotic techniques: single clamp versus partial occluding clamp.

\section{Perspective}

In our study cohort, the use of a partial occluding clamp during construction of proximal coronary anastomoses in CABG procedures does not appear to be associated with an increased incidence of postoperative stroke compared with the single clamp technique.

See Editorial Commentary page 1458.
Postoperative stroke is a rare yet potentially devastating complication after coronary artery bypass grafting (CABG). It is associated with significant reduction in survival and quality of life and a major source of increased

\footnotetext{
From the a Division of Cardiac Surgery, Department of Cardiothoracic Surgery, University of Pittsburgh School of Medicine, Pittsburgh, Pa; ${ }^{\mathrm{b}}$ Department of Cardiovascular and Thoracic Surgery, West Virginia University, Morgantown, WVa; ${ }^{\mathrm{c}}$ Duke Clinical Research Institute, Durham, NC; ${ }^{\mathrm{d}}$ Division of Cardiothoracic Surgery, Department of Surgery, Emory University School of Medicine, Atlanta, Ga; ${ }^{\mathrm{e}}$ Department of Cardiac Surgery, Medstar Washington Hospital Center, Georgetown University, Washington, DC; and ${ }^{\mathrm{f}}$ Division of Cardiovascular Surgery, Johns Hopkins All Children's Heart Institute, Saint Petersburg, Fla.

Received for publication Aug 3, 2017; revisions received March 1, 2018; accepted for publication March 7, 2018; available ahead of print May 10, 2018.

Address for reprints: Danny Chu, MD, FACS, Department of Cardiothoracic Surgery, UPMC Presbyterian Hospital, 200 Lothrop St, C-700, Pittsburgh, PA 15238 (E-mail: chud@upmc.edu).

$0022-5223 / \$ 36.00$

Copyright (c) 2018 by The American Association for Thoracic Surgery

https://doi.org/10.1016/j.jtcvs.2018.03.160
}

health care costs. ${ }^{1}$ Atheroembolism from the ascending aorta is an important source of embolic cerebral infarcts, ${ }^{2}$ and is believed to be related to aortic manipulation. ${ }^{2,3}$

The overwhelming majority of CABG procedures are currently performed with cardiopulmonary bypass on an arrested heart, with most of the proximal anastomoses being constructed using either a single clamp (SC) or partial occluding clamp (POC) technique. The use of a POC for construction of proximal anastomosis has been implicated in increasing risk of postoperative stroke ${ }^{4}$ However,

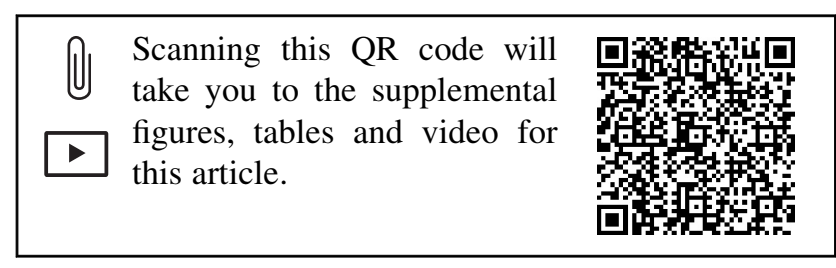




\section{Abbreviations and Acronyms \\ $\mathrm{CABG}=$ coronary artery bypass grafting \\ $\mathrm{CI}=$ confidence interval \\ POC = partial occluding clamp \\ PROPS $=$ predicted risk of postoperative stroke \\ $\mathrm{SC} \quad=$ single clamp \\ STS = Society of Thoracic Surgeons}

controversy persists as to which approach is the safest strategy, especially because several high-volume centers continue to perform $\mathrm{CABG}$ using $\mathrm{POC}$ with acceptable stroke rates. ${ }^{5-7}$

Stroke prevention is an initiative championed by the Society of Thoracic Surgeons (STS) leadership as an overall effort to improve quality of life..$^{8-10}$ The STS database provides a well validated predicted risk of postoperative stroke (PROPS) score, which includes 17 variables for isolated $\mathrm{CABG}$ procedures. Because the incidence of postoperative stroke is a low frequency event, a large patient population is needed to provide adequate power to detect significant differences between the 2 techniques (SC vs POC). We aimed to test our hypothesis that POC use is not associated with increased incidence of postoperative stroke in isolated on-pump CABG patients by using the nationwide multicenter STS Adult Cardiac Surgery Database.

\section{METHODS \\ Data Source}

Because of the retrospective and deidentified nature of the STS database, institutional review boards of Duke University and Duke Clinical Research Institute granted waiver of informed consent for this study. The STS leadership granted authorization for the conduct of this study. Using the national multicenter STS Adult Cardiac Surgery Database (version 2.81) from July 1, 2014 to March 31, 2015, we identified 52,611 patients who underwent on-pump, isolated, primary, nonemergent CABG procedures in participating institutions (Figure 1).

\section{Intervention}

The cohort of 52,611 patients were separated in 2 groups on the basis of whether SC or POC was used for the construction of proximal coronary artery anastomosis onto the ascending aorta on the basis of the STS Adult Cardiac Surgery Database (version 2.81) data field 2710. Data field 2710 was designed to identify the specific technique used for construction of proximal coronary anastomoses during CABG procedures. Specifically, it is coded as: (1) SC, (2) POC, and (3) anastomotic assist device.

\section{Outcomes of Interest}

The primary outcome of interest was incidence of postoperative stroke within 30 days of the index procedure as defined by the STS Adult Cardiac Surgery Database. ${ }^{8-10}$ Secondary outcomes were 30-day surgical mortality, 30-day STS-captured morbidities, length of stay, number of bypass grafts,

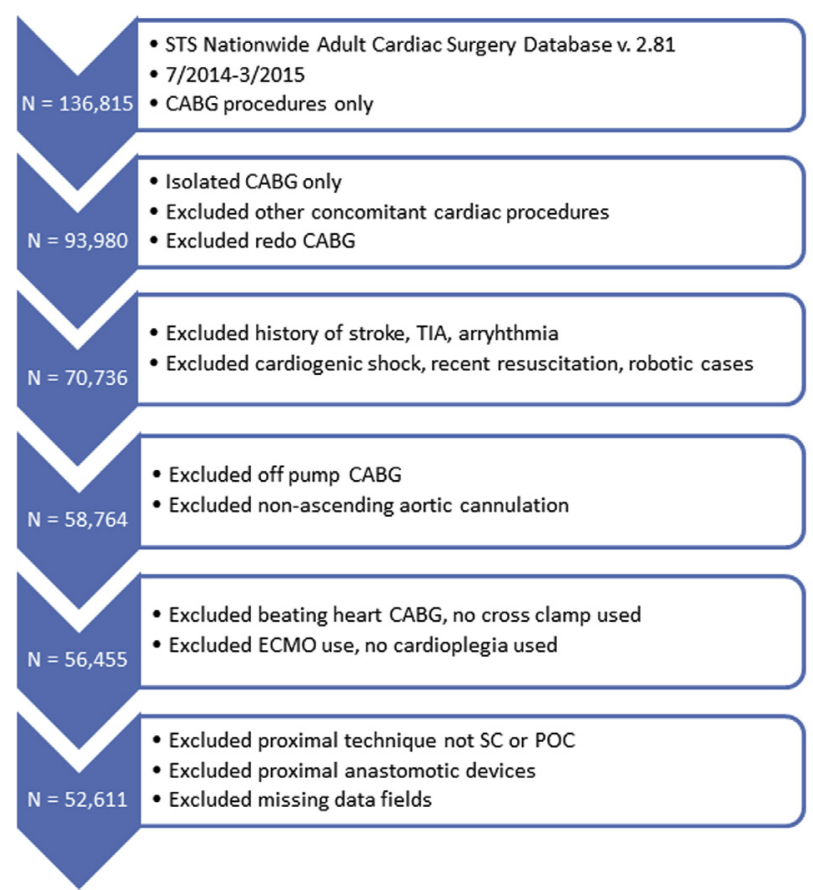

FIGURE 1. Flow diagram algorithm for patient selection. STS, Society of Thoracic Surgeons; $C A B G$, coronary artery bypass grafting; TIA, transient ischemic attack; $E C M O$, extra corporeal membrane oxygenation; $S C$, single clamp; $P O C$, partial occluding clamp.

duration of myocardial ischemia, duration of cardiopulmonary bypass, and readmission within 30 days.

\section{Statistical Analysis}

One-to-one matching propensity scores for POC were calculated on the basis of the STS Isolated CABG Predictive Model for Stroke (body surface area, creatinine, age, cerebral vascular disease, diabetes, number disease vessels, ejection fraction, race, dialysis dependence, gender, gender/body surface area interaction, hypertension, peripheral vascular disease, previous history of myocardial infarction, urgent surgical status) and validated STS PROPS scores. There was a bimodal distribution of SC versus POC techniques among surgeons (Figures E1 and E2 and Table E1). Specifically, most cardiac surgeons $(72 \% ; 1554$ of 2140) routinely use either the SC or POC approach in $>95 \%$ of their cases. A greedy matching algorithm was used to obtain a propensity score matched-pair sample to adjust for differences between the 2 technique groups. To assess balance, we compared the distribution of baseline characteristics in the 2 study groups before and after matching. In the matched sample, absolute value of standardized differences for all variables were $<10$ (or $0.1 \mathrm{SD}$ ), which indicates that balance was achieved with our propensity score matching methods. Missing values for data fields were $<4 \%$ of the data set in general and were not included in propensity score analysis. Surgical times are summarized with median minutes and interquartile range and compared using the nonparametric Wilcoxon test. Unadjusted (in the overall population) and adjusted (in the matched-pair sample) risk ratios (RRs) and 95\% confidence intervals (CIs) were computed to evaluate the effects of aortic clamping strategy on the primary outcome of postoperative stroke and also on surgical mortality, using a modified Poisson model with a log-link function and generalized estimated equations methods to account for hospital clustering of patients. Statistical analyses were performed by Duke Clinical Research Institute with SAS (version 9.3; SAS Institute Inc, Cary, NC). 
TABLE 1. Baseline characteristics before and after propensity score matching

\begin{tabular}{|c|c|c|c|c|c|c|}
\hline \multirow[b]{2}{*}{ Variable } & \multicolumn{3}{|c|}{ Before matching (all patients, $n=52,611$ ) } & \multicolumn{3}{|c|}{ After matching $(\mathrm{n}=\mathbf{3 5 , 6 3 8 )}$} \\
\hline & $\begin{array}{c}\text { SC } \\
(n=34,791)\end{array}$ & $\begin{array}{c}\text { POC } \\
(\mathrm{n}=\mathbf{1 7 , 8 2 0})\end{array}$ & $\begin{array}{l}\text { Standardized } \\
\text { difference, } \%\end{array}$ & $\begin{array}{c}\text { SC } \\
(\mathrm{n}=17, \mathbf{8 1 9})\end{array}$ & $\begin{array}{c}\text { POC } \\
(\mathrm{n}=\mathbf{1 7 , 8 1 9})\end{array}$ & $\begin{array}{l}\text { Standardized } \\
\text { difference, } \%\end{array}$ \\
\hline Age, $y$ & $64.1(10.2)$ & $64.3(10.1)$ & 1.4 & $64.3(10.2)$ & $64.3(10.1)$ & -0.2 \\
\hline BMI & $2.0(0.2)$ & $2.0(0.2)$ & -0.5 & $2.0(0.2)$ & $2.0(0.2)$ & 0.1 \\
\hline Creatinine, $\mathrm{mg} / \mathrm{dL}$ & $1.2(1.0)$ & $1.1(1.0)$ & 0.1 & $1.1(1.0)$ & $1.1(1.0)$ & 0.1 \\
\hline Diabetes, insulin-dependent & $17.1(5960)$ & $16.4(2928)$ & -1.9 & $16.3(2910)$ & $16.4(2928)$ & 0.3 \\
\hline Diabetes, not receiving insulin & $29.2(10,180)$ & $30.0(5337)$ & 1.5 & $29.6(5282)$ & $30.0(5337)$ & 0.7 \\
\hline Ejection fraction & $52.7(11.9)$ & $52.5(11.9)$ & -1.5 & $52.5(12.5)$ & $52.5(12.0)$ & 0.1 \\
\hline Black race & $7.4(2588)$ & $7.3(1306)$ & -0.4 & $7.3(1295)$ & $7.3(1306)$ & 0.2 \\
\hline $\begin{array}{l}\text { Congestive heart failure and NYHA } \\
\text { III or IV }\end{array}$ & $9.0(3128)$ & $7.8(1388)$ & -4.3 & $9.0(1600)$ & $7.8(1390)$ & -4.3 \\
\hline $\begin{array}{l}\text { Chronic lung disease: moderate to } \\
\text { severe }\end{array}$ & $8.7(3027)$ & $9.2(1632)$ & 1.6 & $8.7(1556)$ & $9.2(1632)$ & 1.5 \\
\hline CVD & $9.6(3326)$ & $9.7(1730)$ & 0.5 & $9.5(1689)$ & $9.7(1730)$ & 0.8 \\
\hline Renal failure, dialysis & $2.6(887)$ & $2.3(403)$ & -1.9 & $2.3(415)$ & $2.3(403)$ & -0.5 \\
\hline Female sex & $24.0(8357)$ & $23.6(4206)$ & -1.0 & $23.7(4225)$ & $23.6(4205)$ & -0.3 \\
\hline Hispanic race & $6.1(2105)$ & $6.6(1181)$ & 2.4 & $6.7(1196)$ & $6.6(1181)$ & -0.3 \\
\hline Hypertension & $87.8(30,553)$ & $87.3(15,550)$ & -1.7 & $87.3(15,554)$ & $87.3(15,549)$ & -0.1 \\
\hline Other race & $0.4(153)$ & $0.5(91)$ & 1.0 & $0.4(77)$ & $0.5(91)$ & 1.1 \\
\hline PVD & 11.9 (4147) & $11.8(2094)$ & -0.5 & $11.5(2056)$ & $11.8(2094)$ & 0.6 \\
\hline White race & $78.5(27,311)$ & $79.4(14,142)$ & 2.1 & $78.6(13,999)$ & $79.3(14,141)$ & 2.0 \\
\hline $\mathrm{MI}<21 \mathrm{~d}$ & $29.5(10,270)$ & $30.6(5444)$ & 2.2 & $30.7(5470)$ & $30.6(5444)$ & -0.3 \\
\hline Status, urgent & $59.0(20,513)$ & $61.2(10,908)$ & 4.6 & $61.2(10,905)$ & $61.2(10,909)$ & 0.02 \\
\hline Unstable angina & $38.8(13,513)$ & $38.6(6873)$ & -0.6 & $39.0(6941)$ & $38.6(6873)$ & -0.8 \\
\hline
\end{tabular}

Data presented as mean (SD) or percentage (absolute number). SC, Single clamp; POC, partial occluding clamp; BMI, body mass index; NYHA, New York Heart Association; $C V D$, cerebral vascular disease; $P V D$, peripheral vascular disease; $M I$, myocardial infarction.

\section{RESULTS}

\section{Baseline Characteristics}

Table 1 shows baseline patient-level characteristics before and after propensity score matching. Propensity score for the one-to-one matched cohort of the SC group $(\mathrm{n}=17,819)$ and the POC group $(\mathrm{n}=17,819)$ did not differ significantly in any of the STS PROPS patient-level characteristics (standardized difference $<10$; Table 1).

\section{Surgical Characteristics}

Table 2 shows specific intraoperative parameters for the propensity score matched cohort. Despite similar numbers of arterial and venous conduits, the SC group incurred longer cardiopulmonary and myocardial ischemic times compared with the POC group.

\section{Outcome Measures}

Table E2 shows descriptive analyses of all unadjusted crude postoperative outcomes for the unmatched cohort including primary and secondary end points. Outcome measures were generally similar for the propensity-matched cohort in nearly all prespecified fields with the exception of postoperative renal failure, which was slightly higher $(0.3 \%$ increase in incidence) in the POC group (Table 3$)$. The risk-adjusted primary end point of 30-day postoperative stroke occurred with similar frequency in both matched cohorts (SC $0.9 \%$ vs POC $1.1 \%$; relative risk, $1.1 ; 95 \% \mathrm{CI}$, $0.9-1.4 ; P=.3$ ) as were mortality rates (SC $1.3 \%$ vs POC $1.3 \%$; relative risk, $1.0 ; 95 \% \mathrm{CI}, 0.8-1.2 ; P=.9$; Table 4). With the exception of a small increase in the relative risk of renal failure, the POC group did not appear to be associated with any other increased risk of STS-captured complications (Table 4). Table E3 shows similar outcomes findings for both unmatched and propensity-matched cohorts using multivariate regression methods.

\section{DISCUSSION}

Results of our study supported that the manner in which proximal grafts are constructed (SC vs POC) did not affect stroke incidence or mortality after isolated primary CABG. Despite more physical manipulation of the ascending aorta with the POC technique, postoperative stroke rates remained equivalent compared with the $\mathrm{SC}$ technique in our large risk-adjusted propensity matched cohort. 
TABLE 2. Surgical characteristics of propensity score matched cohort

\begin{tabular}{|c|c|c|c|c|}
\hline Variable & Overall $(\mathbf{n}=\mathbf{3 5 , 6 3 8})$ & $\operatorname{SC}$ group $(n=17,819)$ & POC group $(n=17,819)$ & $P$ value \\
\hline CPB time, $\min$ & $92.3(34.8)$ & $95.0(35.0)$ & $89.7(34.4)$ & $<.0001$ \\
\hline Cross-clamp time, min & $65.6(27.8)$ & $74.1(29.2)$ & $57.0(23.3)$ & $<.0001$ \\
\hline Lowest temperature on $\mathrm{CPB},{ }^{\circ} \mathrm{C}$ & $33.4(2.1)$ & $33.4(2.1)$ & $33.3(2.2)$ & $<.0001$ \\
\hline \multicolumn{5}{|l|}{ Grafts } \\
\hline Number of distal anastomoses with arterial conduits & $1.1(0.5)$ & $1.1(0.5)$ & $1.1(0.4)$ & 1.0 \\
\hline Number of distal anastomoses with venous conduits & $2.3(1.0)$ & $2.2(1.0)$ & $2.3(1.0)$ & 1.0 \\
\hline \multicolumn{5}{|l|}{ IMA used for grafts } \\
\hline No IMA & $2.7(967)$ & $2.5(446)$ & $2.9(521)$ & $<.0001$ \\
\hline Both IMAs & $4.5(1599)$ & $5.3(944)$ & $3.7(655)$ & \\
\hline Right IMA & $0.4(133)$ & $0.4(75)$ & $0.3(58)$ & \\
\hline Left IMA & $92.4(32,936)$ & $91.8(16,353)$ & $93.1(16,583)$ & \\
\hline Number of total distal anastomoses done with IMA grafts & $1.1(0.3)$ & $1.1(0.3)$ & $1.1(0.3)$ & 1.0 \\
\hline
\end{tabular}

Recent single institutional data from a well reputed highvolume tertiary referral center showed a 2.6-fold increase in the incidence of postoperative stroke after on-pump CABG using POC compared with SC techniques. ${ }^{4}$ However, these findings were not observed in a similar analysis of nearly 2000 patients. ${ }^{5}$ Because of the relatively low frequency of postoperative stroke, a larger sample size appeared to be necessary to discern any clinically and/or statistically significant differences. Data field 2710 (proximal coronary anastomotic technique) is a new data field addition to the
STS Adult Cardiac Surgery Database version 2.81 started on July 1, 2014. Therefore, the most contemporary sample available from the nationwide multicenter STS Adult Cardiac Surgery Database was used to achieve adequate power to address the controversy between SC and POC techniques.

Our current analysis of $>35,000$ propensity matched isolated CABG patients failed to reveal any clinically or statistically significant difference in stroke rate or mortality, other than shorter ischemic and perfusion times with the POC technique. The 2 groups of patients were balanced

TABLE 3. Outcome measures of propensity score matched cohort

\begin{tabular}{|c|c|c|c|c|c|c|c|}
\hline \multirow[b]{2}{*}{ Variable } & \multicolumn{2}{|c|}{ Overall $(n=35,638)$} & \multicolumn{2}{|c|}{ SC group $(n=17,819)$} & \multicolumn{2}{|c|}{ POC group $(n=17,819)$} & \multirow[b]{2}{*}{$P$ value } \\
\hline & Absolute number & $\%$ & Absolute number & $\%$ & Absolute number & $\%$ & \\
\hline Surgical mortality & 448 & 1.3 & 225 & 1.3 & 223 & 1.3 & .9 \\
\hline \multicolumn{8}{|l|}{ Major stroke morbidity } \\
\hline Permanent stroke & 356 & 1.0 & 168 & 0.9 & 188 & 1.1 & .3 \\
\hline TIA & 62 & 0.2 & 27 & 0.2 & 35 & 0.2 & .3 \\
\hline \multicolumn{8}{|l|}{ Encephalopathy } \\
\hline Other & 89 & 0.3 & 46 & 0.3 & 43 & 0.2 & .2 \\
\hline Intracranial bleeding & 5 & 0.01 & 1 & 0.01 & 4 & 0.02 & \\
\hline Metabolic & 214 & 0.6 & 101 & 0.6 & 113 & 0.6 & \\
\hline Drug & 56 & 0.2 & 36 & 0.2 & 20 & 0.1 & \\
\hline Embolic & 36 & 0.1 & 21 & 0.1 & 15 & 0.08 & \\
\hline Anoxic & 56 & 0.2 & 28 & 0.2 & 28 & 0.2 & \\
\hline Paralysis & 48 & 0.1 & 26 & 0.2 & 22 & 0.1 & .6 \\
\hline \multicolumn{8}{|l|}{ Major morbidity } \\
\hline Any reoperation & 677 & 1.9 & 318 & 1.8 & 359 & 2.01 & .1 \\
\hline Bleeding/tamponade reoperation & 525 & 1.5 & 266 & 1.5 & 259 & 1.5 & .8 \\
\hline Prolonged ventilation & 2006 & 5.6 & 1009 & 5.7 & 997 & 5.6 & .8 \\
\hline Renal failure if no previous dialysis and creatinine $<4 \mathrm{mg} / \mathrm{dL}$ & 470 & 1.4 & 207 & 1.2 & 263 & 1.5 & .01 \\
\hline \multicolumn{8}{|l|}{ Other complications } \\
\hline Pacemaker/ICD & 330 & 0.9 & 156 & 0.9 & 174 & 1.0 & .3 \\
\hline Pneumonia & 686 & 1.9 & 341 & 1.9 & 345 & 1.9 & .9 \\
\hline Length of stay $<6 \mathrm{~d}$ & 18,416 & 51.7 & 9272 & 52.0 & 9144 & 51.3 & .2 \\
\hline Readmission $\leq 30$ days from procedure (among alive) & 3097 & 8.8 & 1581 & 9.0 & 1516 & 8.6 & .2 \\
\hline
\end{tabular}

SC, Single clamp; POC, partial occluding clamp; TIA, transient ischemic attack; ICD, implantable cardioverter-defibrillator. 
TABLE 4. Outcomes after propensity score matching

\begin{tabular}{|c|c|c|c|c|c|}
\hline Outcomes & Events, $\mathbf{n}$ & $\mathbf{R R}$ & $\begin{array}{c}\text { Lower } \\
\mathbf{9 5} \% \text { CI }\end{array}$ & $\begin{array}{c}\text { Upper } \\
95 \% \text { CI }\end{array}$ & $P$ value \\
\hline Mortality & 448 & 0.99 & 0.81 & 1.21 & .9 \\
\hline Permanent stroke & 356 & 1.12 & 0.90 & 1.39 & .3 \\
\hline TIA & 62 & 1.30 & 0.77 & 2.18 & .3 \\
\hline Encephalopathy & 456 & 0.96 & 0.74 & 1.24 & .7 \\
\hline Paralysis & 48 & 0.85 & 0.47 & 1.51 & .6 \\
\hline Any reoperation & 677 & 1.13 & 0.96 & 1.33 & .1 \\
\hline Bleeding/tamponade reoperation & 525 & 0.97 & 0.81 & 1.16 & .8 \\
\hline New RF (no previous RF) & 472 & 1.26 & 1.04 & 1.52 & .02 \\
\hline Prolonged ventilation & 2006 & 0.99 & 0.89 & 1.10 & .8 \\
\hline Pneumonia & 686 & 1.01 & 0.84 & 1.23 & .9 \\
\hline Pacemaker/ICD & 330 & 1.12 & 0.88 & 1.42 & .4 \\
\hline Length of stay $<6 \mathrm{~d}$ & 18,416 & 0.99 & 0.94 & 1.03 & .5 \\
\hline Readmission: $30 \mathrm{~d}$ & 3097 & 0.96 & 0.89 & 1.04 & .3 \\
\hline
\end{tabular}

RR ratios calculated for POC (SC as reference). $R R$, Relative risk; $C I$, confidence interval; $T I A$, transient ischemic attack; $R F$, renal failure; $I C D$, implantable cardioverter-defibrillator.

using a propensity score matching algorithm by equilibrating their STS PROPS scores. The incidence of postoperative stroke for SC and POC were $0.9 \%$ and $1.1 \%$, respectively.

SC proponents argue that this technique minimizes aortic manipulation and logically should reduce postoperative stroke from atheroembolism. ${ }^{2-4}$ Partial occluding clamp proponents argue, however, that the SC technique prolongs myocardial ischemic time, and increases the risk

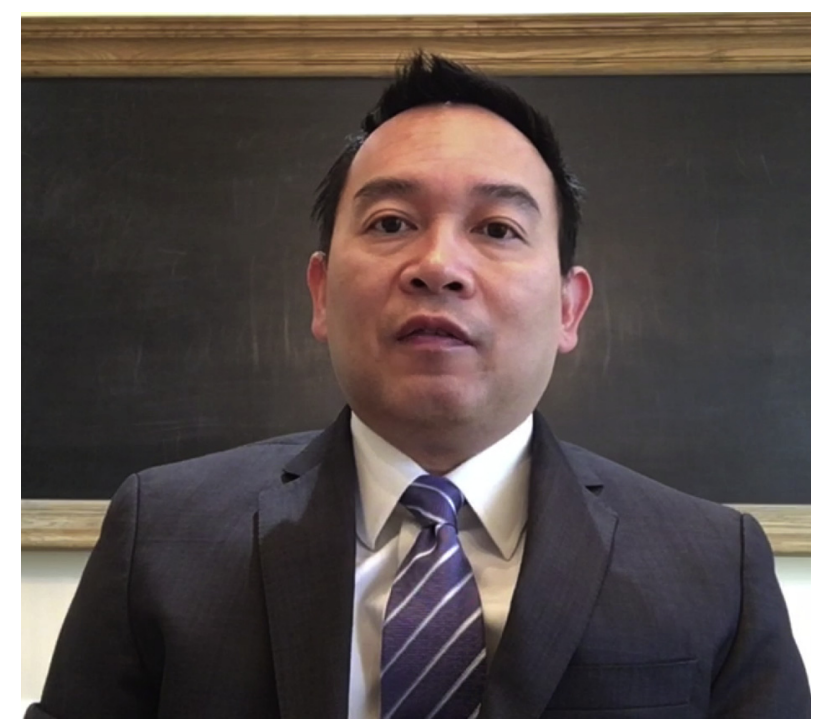

VIDEO 1. Video of senior and corresponding author, Dr Danny Chu, summarizing the study and its associated relevance. Video available at: https://www.jtcvs.org/article/S0022-5223(18)30983-8/fulltext. for cardiac and cerebral air embolism. The fact that neither technique was superior in preventing postoperative stroke, might be because there are other factors that are not accounted for such as aortic cannulation, ${ }^{11}$ cannula type and size, perfusion jet, and aortic punch. ${ }^{6}$ This is also shown in an experimental study by Grocott et al. The study evaluated the S100B serum level during each phase of the CABG. S100B is a protein marker of cerebral injury. It showed that serum levels of S100B are highest at initial aortic cannulation rather than at cross-clamp application or removal. ${ }^{11}$ The no touch technique was described in 1981 by Mills and Everson, who performed CABG procedures with no central aortic manipulation, low-flow hypothermia fibrillatory arrest, and constructed all proximal anastomoses in an end-to-side fashion to the internal mammary artery. They reported no cerebral complications. ${ }^{12}$ Off-pump CABG had once gained popularity in an attempt to mitigate early postoperative neurocognitive dysfunction in addition to other benefits. ${ }^{13}$ Recent analysis showed a lower incidence of postoperative stroke using off-pump, no-clamp technique compared with off-pump, POC technique with relative risk stroke reduction of $0.83 .{ }^{4}$ However, concerns over lower graft patency and poor midterm survival have limited widespread adoption of off-pump CABG (Randomized On/Off Bypass [ROOBY] study group). ${ }^{14,15}$ Therefore, there might be variables other than the $\mathrm{SC}$ or $\mathrm{POC}$ technique that influence postoperative stroke after CABG. ${ }^{16-18}$

With the advent of transcatheter aortic valve replacement, more information regarding the burden and location of thoracic aortic calcifications were available. A population-based cohort study of 2400 elderly patients 
showed a relative sparing of aortic calcifications in proximal ascending aortas. ${ }^{19}$ This anatomic result might support our current finding that the use of POC on a relatively normal proximal ascending aorta was not associated with increased postoperative stroke and that the etiology of postoperative stroke after isolated CABG might be from aortic cannulation and/or cross clamping in distal ascending aorta/ proximal aortic arch.

Surgeons who used the POC technique might sometimes reposition the POC clamp numerous times for different locations of proximal coronary anastomosis on the ascending aorta. With this potential increased manipulation of the ascending aorta, it is possible that higher number of proximal anastomoses might further increase incidence of postoperative stroke. To evaluate this potential confounding variable, we use the number of distal venous anastomoses as a proxy for number of proximal aortic anastomoses (because the STS database does not capture the exact number of proximal anastomoses) to performed a multiplicative interaction analyses for matched as well as unmatched cohorts (Table E4). This separate analysis revealed that the number of distal venous anastomoses does not have any interactive correlative effect on the primary outcome of postoperative stroke in matched as well as unmatched cohorts.

The risk-adjusted outcomes (Table 4) were generally similar in SC as well as POC cohorts with the exception of postoperative incidence of renal failure as defined by the STS Adult Cardiac Surgery Database. ${ }^{9}$ Specifically, the POC cohort posed a $26 \%$ increase in the incidence of postoperative renal failure despite shorter perfusion and myocardial ischemic times compared with SC group. The rationale of this unexpected finding is unclear on the basis of our current study design. In general, etiology of postoperative renal failure after cardiac surgery is likely multifactorial and is not yet fully understood as evident by a comprehensive systematic review of the literature. ${ }^{20}$ Our current study was designed for the primary intent of determining whether aortic clamping strategy affects postoperative stroke. Because the incidence of postoperative renal failure was not our primary outcome of interest, there might be potential confounding variables that were simply not captured by the STS database.

Our study has some limitations adherent to its retrospective design. Although this study represents one of the largest studies to date in addressing the SC versus POC controversy, the retrospective nature of the study does not account for potential confounding variables not captured by the STS database. Only half of the patients in our entire prematched cohort $(50.6 \% ; 26,616$ of 52,611$)$ had a documented assessment of the ascending aorta with epiaortic ultrasound. As a result, we were unable to accurately elucidate whether the assessment of the ascending aorta affected our primary outcome. Nevertheless, among the population that had documented assessment of ascending aorta with epiaortic ultrasound only $1.0 \%$ (267 of 26,616) had their surgical plans altered. Other potential confounding factors include presence of aortic atheroma, lack of neurology specialist to evaluate the presence of postoperative stroke, and lack of consistent parameters or objective radiographic evaluations for diagnosis of postoperative stroke.

\section{CONCLUSIONS}

In our current multicenter observational study, we were unable to detect any significant differences in 30-day incidence of postoperative stroke for $\mathrm{CABG}$ patients regardless of the techniques used (SC vs POC) in constructing proximal coronary anastomoses. Postoperative stroke incidence is not insignificant in CABG patients. In consideration of intraoperative clinical scenarios, our current study suggested that either approach (SC or POC) may be used successfully without incurring differential increase risk of postoperative stroke. Video 1 is a brief summary of the findings and conclusion of this study. Future large multicenter prospective randomized control trials are needed to address this continued controversy of SC and POC techniques for performing proximal coronary anastomoses in $\mathrm{CABG}$ procedures with the ultimate goal of decreasing postoperative stroke incidence to zero.

\section{Conflict of Interest Statement}

Authors have nothing to disclose with regard to commercial support.

\section{References}

1. Messé SR, Acker MA, Kasner SE, Fanning M, Giovannetti T, Ratcliffe SJ, et al. Stroke after aortic valve surgery: results from a prospective cohort. Circulation. 2014; 129:2253-61.

2. Blauth CI, Cosgrove DM, Webb BW, Ratliff NB, Boylan M, Piedmonte MR, et al. Atheroembolism from the ascending aorta: an emerging problem in cardiac surgery. J Thorac Cardiovasc Surg. 1992;103:1104-12.

3. Stefaniszyn HJ, Novick RJ, Sheldon H, Sniderman AD, Salerno TA. Anatomical observations in cadavers during the application of a partial exclusion clamp to the ascending aorta. Curr Surg. 1984;41:184-7.

4. Daniel WT III, Kilgo P, Puskas JD, Thourani VH, Lattouf OM, Guyton RA, et al. Trends in aortic clamp use during coronary artery bypass surgery: effect of aortic clamping strategies on neurologic outcomes. J Thorac Cardiovasc Surg. 2014; 147:652-7.

5. Chu D, Schaheen L, Morell VO, Gleason TG, Cook CC, Wei LM, et al. Effect of aortic clamping strategy on postoperative stroke in coronary artery bypass grafting operations. JAMA Surg. 2016;151:59-62.

6. Kim RW, Mariconda DC, Tellides G, Kopf GS, Dewar ML, Lin Z, et al. Singleclamp technique does not protect against cerebrovascular accident in coronary artery bypass grafting. Eur J Cardiothorac Surg. 2001;20:127-32.

7. Araque JC, Greason KL, Li Z, Heins CN, Stulak JM, Daly RC, et al. On-pump coronary artery bypass graft operation: is one crossclamp application better than two? J Thorac Cardiovasc Surg. 2015;150:145-9.

8. O'Brien SM, Shahian DM, DeLong ER, Normand SL, Edwards FH, Ferraris VA, et al. Quality measurement in adult cardiac surgery, part 2: statistical considerations in composite measure scoring and provider rating. Ann Thorac Surg. 2007;83:S13-26.

9. Shahian DM, Edwards FH, Ferraris VA, Haan CK, Rich JB, Normand SL, et al. Society of Thoracic Surgeons quality measurement task force: quality measurement in adult cardiac surgery, part 1: conceptual framework and measure selection. Ann Thorac Surg. 2007;83:S3-12. 
10. Shahian DM, He X, Jacobs JP, Rankin JS, Welke KF, Edwards FH, et al. The STS AVR + CABG composite score: a report of the STS quality measurement task force. Ann Thorac Surg. 2014;97:1604-9.

11. Grocott HP, Croughwell ND, Amory DW, White WD, Kirchner JL, Newman MF. Cerebral emboli and serum S100B during cardiac operations. Ann Thorac Surg. 1998;65:1645-50.

12. Mills NL, Everson CT. Atherosclerosis of the ascending aorta and coronary artery bypass: pathology, clinical correlates, and operative management. J Thorac Cardiovasc Surg. 1991;102:546-53.

13. Sellke FW, DiMaio JM, Caplan LR, Ferguson TB, Gardner TJ, Hiratzka LF, et al. Comparing on-pump and off-pump coronary artery bypass grafting: numerous studies but few conclusions: a scientific statement from the American Heart Association council on cardiovascular surgery and anesthesia in collaboration with the interdisciplinary working group on quality of care and outcomes research. Circulation. 2005;111:2858-64.

14. Hattler B, Messenger JC, Shroyer AL, Collins JF, Haugen SJ, Garcia JA, et al. Offpump coronary artery bypass surgery is associated with worse arterial and saphenous vein graft patency and less effective revascularization: results from the veterans affairs randomized on/off bypass (ROOBY) trial. Circulation. 2012;125:2827-35.
15. Shroyer AL, Hattler B, Wagner TH, Collins JF, Baltz JH, Quin JA, et al. Five-year outcomes after on-pump and off-pump coronary-artery bypass. $N$ Engl J Med. 2017;377:623-32.

16. Lawton JS. Respect the aorta. J Thorac Cardiovasc Surg. 2015;150:150-1.

17. Mao Z, Zhong X, Yin J, Zhao Z, Hu X, Hackett ML. Predictors associated with stroke after coronary artery bypass grafting: a systematic review. J Neurol Sci. 2015;357:1-7.

18. Nah HW, Lee JW, Chung CH, Choo SJ, Kwon SU, Kim JS, et al. New brain infarcts on magnetic resonance imaging after coronary artery bypass graft surgery: lesion patterns, mechanism, and predictors. Ann Neurol. 2014;76: 347-55.

19. Bos D, Leening MJ, Kavousi M, Hofman A, Franco OH, van der Lugt A, et al. Comparison of atherosclerotic calcification in major vessel beds on the risk of all-cause and cause-specific mortality: the Rotterdam Study. Circ Cardiovasc Imaging. 2015;8:e003843.

20. Huen S, Parikh CR. Predicting acute kidney injury following cardiac surgery: a systematic review. Ann Thorac Surg. 2012;93:337-47.

Key Words: CABG, stroke, database 


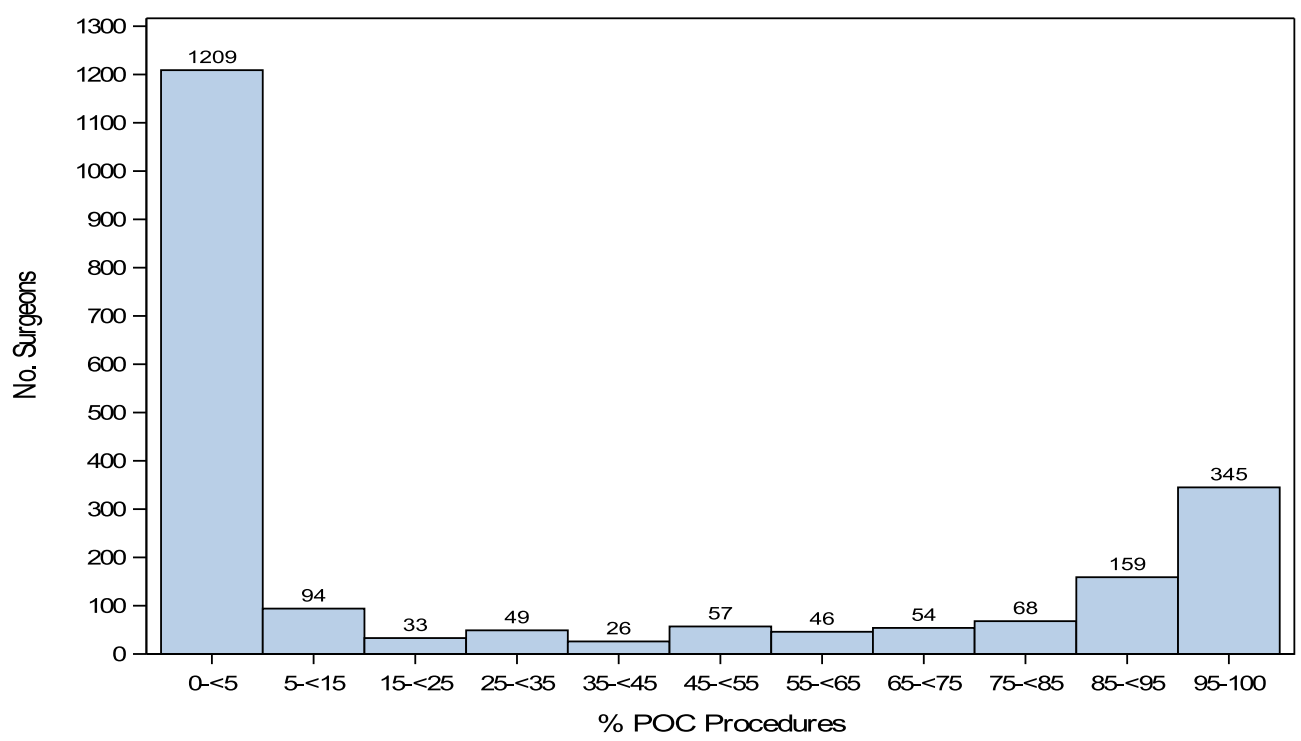

FIGURE E1. Histograms for percentage of POC according to surgeons, counts indicate number of surgeons in each bin (percentage of POC patients for each surgeon). $P O C$, Partial occluding clamp.

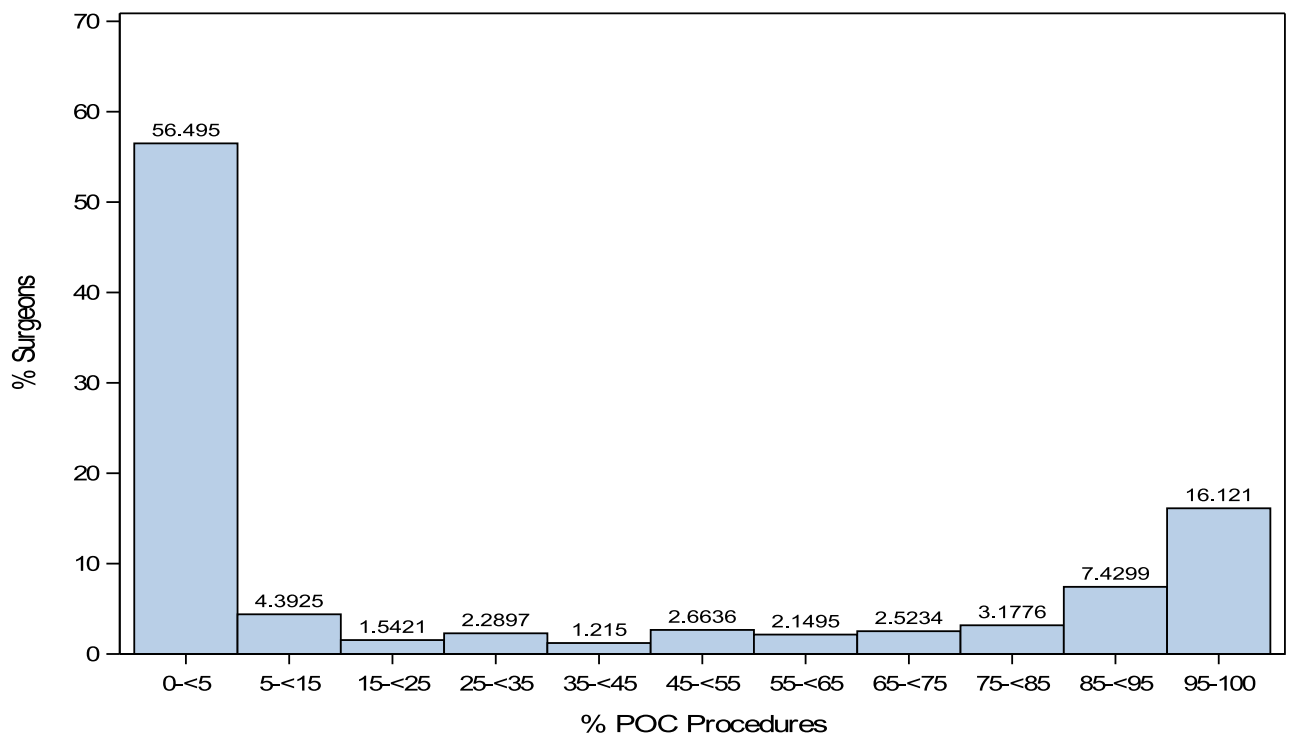

FIGURE E2. Histograms for percentage of POC according to surgeons, percentages indicate percent of surgeons (of total surgeons) in each bin (percentage of POC patients for each surgeon). Conclusion: There are $56 \%$ of surgeons $(n=1209)$ with $<5 \%$ partial occluding clamp patients and $16 \%(n=345)$ with $\geq 95 \%$ partial occluding clamp patients. POC, Partial occluding clamp. 
TABLE E1. Among all surgeons, how many have all POC patients and how many none

\begin{tabular}{lccc}
\hline Total surgeons & $\begin{array}{c}\text { Surgeons with } \\
\text { no POC cases, } \mathbf{n}\end{array}$ & $\begin{array}{c}\text { Percentage of surgeons } \\
\text { with no POC cases }\end{array}$ & $\begin{array}{c}\text { Surgeons with all } \\
\text { POC cases, } \mathbf{n}\end{array}$ \\
\hline 2140 & 1123 & 52.47664 & 259 \\
\hline$P O C$, Partial occluding clamp. & & 12.1028 & $\begin{array}{c}\text { Percentage of surgeons } \\
\text { with all POC cases }\end{array}$ \\
\hline
\end{tabular}

POC, Partial occluding clamp.

TABLE E2. Unadjusted outcomes for unmatched cohort

\begin{tabular}{|c|c|c|c|c|c|c|}
\hline \multirow[b]{2}{*}{ Variable } & \multicolumn{2}{|c|}{ Overall $(n=52,611)$} & \multicolumn{2}{|c|}{ SC group $(n=34,791)$} & \multicolumn{2}{|c|}{ POC group $(n=17,820)$} \\
\hline & Absolute number & $\%$ & Absolute number & $\%$ & Absolute number & $\%$ \\
\hline Surgical mortality & 650 & 1.2 & 427 & 1.2 & 223 & 1.3 \\
\hline \multicolumn{7}{|l|}{ Major stroke morbidity } \\
\hline Permanent stroke & 534 & 1.0 & 346 & 1.0 & 188 & 1.1 \\
\hline TIA & 93 & 0.2 & 58 & 0.2 & 35 & 0.2 \\
\hline \multicolumn{7}{|l|}{ Encephalopathy } \\
\hline Other & 128 & 0.2 & 85 & 0.2 & 43 & 0.2 \\
\hline Intracranial bleeding & 6 & 0.01 & 2 & 0.01 & 4 & 0.02 \\
\hline Metabolic & 340 & 0.7 & 227 & 0.7 & 113 & 0.6 \\
\hline Drug & 92 & 0.2 & 72 & 0.2 & 20 & 0.1 \\
\hline Embolic & 54 & 0.1 & 39 & 0.1 & 15 & 0.1 \\
\hline Anoxic & 79 & 0.2 & 51 & 0.2 & 28 & 0.2 \\
\hline Paralysis & 72 & 0.1 & 50 & 0.1 & 22 & 0.1 \\
\hline \multicolumn{7}{|l|}{ Paralysis type } \\
\hline Permanent & 45 & 62.5 & 32 & 64.0 & 13 & 59.1 \\
\hline Transient & 26 & 36.1 & 17 & 34.0 & 9 & 40.9 \\
\hline \multicolumn{7}{|l|}{ Major morbidity } \\
\hline $\begin{array}{l}\text { Any reoperation (bleeding/valve/graft/other } \\
\text { cardiac dysfunction) }\end{array}$ & 997 & 1.9 & 638 & 1.8 & 359 & 2.0 \\
\hline Reoperation for bleeding/tamponade & 778 & 1.5 & 519 & 1.5 & 259 & 1.5 \\
\hline Mediastinitis & 0 & 0 & 0 & 0 & 0 & 0 \\
\hline Prolonged ventilation & 2945 & 5.6 & 1948 & 5.6 & 997 & 5.6 \\
\hline $\begin{array}{l}\text { Renal failure if no previous dialysis and creatinine } \\
<4 \mathrm{mg} / \mathrm{dL}\end{array}$ & 704 & 1.4 & 441 & 1.3 & 263 & 1.5 \\
\hline \multicolumn{7}{|l|}{ Other complications } \\
\hline \multicolumn{7}{|l|}{ Permanent devices for rhythm disturbance } \\
\hline Pacemaker/ICD & 474 & 0.9 & 300 & 0.9 & 174 & 1.0 \\
\hline Pneumonia & 1013 & 1.9 & 668 & 1.9 & 345 & 1.9 \\
\hline Aortic dissection & 14 & 0.03 & 8 & 0.02 & 6 & 0.03 \\
\hline \multicolumn{7}{|l|}{ Readmission (among alive) } \\
\hline Readmission $\leq 30$ days from procedure & 4560 & 8.8 & 3043 & 8.9 & 1517 & 8.6 \\
\hline
\end{tabular}

$S C$, Single clamp; $P O C$, partial occluding clamp; $T I A$, transient ischemic attack; $I C D$, implantable cardioverter-defibrillator. 
TABLE E3. Multivariate regression analyses

\begin{tabular}{|c|c|c|c|c|c|c|c|c|}
\hline \multirow[b]{2}{*}{ Outcome } & \multicolumn{4}{|c|}{ Unmatched cohort } & \multicolumn{4}{|c|}{ Propensity score matched cohort } \\
\hline & $\overline{\mathbf{R R}}$ & Lower 95\% CI & Upper 95\% CI & $P$ value & $\overline{\mathbf{R R}}$ & Lower 95\% CI & Upper 95\% CI & $P$ value \\
\hline Mortality & 1.02 & 0.85 & 1.22 & .8 & 1.00 & 0.82 & 1.23 & 1.0 \\
\hline Permanent stroke & 1.05 & 0.88 & 1.26 & 6 & 1.12 & 0.90 & 1.39 & .3 \\
\hline Encephalopathy & 0.91 & 0.71 & 1.17 & .5 & 0.96 & 0.75 & 1.24 & .8 \\
\hline Any reoperation & 1.09 & 0.94 & 1.26 & .2 & 1.13 & 0.96 & 1.33 & .1 \\
\hline Bleeding/tamponade reoperation & 0.97 & 0.83 & 1.13 & .7 & 0.97 & 0.81 & 1.16 & .8 \\
\hline New RF (no previous RF) & 1.16 & 0.98 & 1.37 & .09 & 1.27 & 1.05 & 1.54 & .01 \\
\hline Prolonged ventilation & 0.99 & 0.90 & 1.09 & .9 & 0.99 & 0.89 & 1.11 & .9 \\
\hline Pneumonia & 1.00 & 0.84 & 1.19 & 1.0 & 1.02 & 0.84 & 1.23 & .9 \\
\hline Pacemaker/ICD & 1.13 & 0.91 & 1.40 & .3 & 1.14 & 0.89 & 1.45 & .3 \\
\hline Length of stay $<6 \mathrm{~d}$ & 0.99 & 0.95 & 1.04 & .7 & 0.99 & 0.94 & 1.03 & .5 \\
\hline Readmission: $30 \mathrm{~d}$ & 0.98 & 0.91 & 1.05 & .5 & 0.96 & 0.89 & 1.04 & .3 \\
\hline
\end{tabular}

Relative risk ratios calculated for POC (SC as reference). $R R$, Relative risk; $C I$, confidence interval; $R F$, renal failure; $I C D$, implantable cardioverter-defibrillator. 
TABLE E4. Interactive effect of distal venous anastomoses

\begin{tabular}{|c|c|c|c|c|c|c|c|c|c|c|c|}
\hline \multirow[b]{3}{*}{ In-hospital outcomes } & k ratios for $P$ & OC vs & SC accor & ling to nu & nber of $\mathbf{d i}$ & stal anastom & sis-r & enous con & duits & & \\
\hline & \multirow{2}{*}{$\begin{array}{c}\text { Number of } \\
\text { distal } \\
\text { anastomosis }\end{array}$} & \multicolumn{5}{|c|}{ Unmatched population } & \multicolumn{5}{|c|}{ Matched sample } \\
\hline & & $\mathbf{R R}$ & $\begin{array}{c}\text { Lower } \\
\mathbf{9 5} \% \text { CI }\end{array}$ & $\begin{array}{c}\text { Upper } \\
95 \% \text { CI }\end{array}$ & $P$ value & $\begin{array}{c}\text { Interaction } \\
P \text { value }\end{array}$ & RR & $\begin{array}{c}\text { Lower } \\
95 \% \text { CI }\end{array}$ & $\begin{array}{c}\text { Upper } \\
95 \% \text { CI }\end{array}$ & $P$ value & $\begin{array}{c}\text { Interaction } \\
P \text { value }\end{array}$ \\
\hline \multirow[t]{3}{*}{ Permanent stroke } & 0 to 1 & 0.87 & 0.52 & 1.46 & .6 & .7 & 0.98 & 0.53 & 1.79 & .9 & .7 \\
\hline & 2 to 3 & 1.05 & 0.86 & 1.30 & .6 & & 1.17 & 0.91 & 1.51 & .2 & \\
\hline & $>3$ & 1.20 & 0.72 & 1.98 & .5 & & 0.91 & 0.52 & 1.58 & .7 & \\
\hline \multirow[t]{3}{*}{ Surgical mortality } & 0 to 1 & 1.09 & 0.71 & 1.68 & .7 & .7 & 1.10 & 0.69 & 1.78 & .7 & .7 \\
\hline & 2 to 3 & 1.02 & 0.84 & 1.25 & .8 & & 0.99 & 0.79 & 1.24 & .9 & \\
\hline & $>3$ & 0.84 & 0.50 & 1.41 & .5 & & 0.80 & 0.45 & 1.44 & .5 & \\
\hline \multirow[t]{3}{*}{ TIA } & 0 to 1 & 1.42 & 0.50 & 4.03 & .5 & .8 & 1.75 & 0.49 & 6.20 & .4 & .4 \\
\hline & 2 to 3 & 1.19 & 0.72 & 1.97 & .5 & & 1.40 & 0.77 & 2.55 & .3 & \\
\hline & $>3$ & 0.75 & 0.20 & 2.82 & .7 & & 0.55 & 0.13 & 2.23 & .4 & \\
\hline \multirow[t]{3}{*}{ Encephalopathy } & 0 to 1 & 1.08 & 0.67 & 1.73 & .8 & .2 & 1.25 & 0.75 & 2.10 & .4 & .1 \\
\hline & 2 to 3 & 0.83 & 0.64 & 1.08 & .2 & & 0.84 & 0.64 & 1.12 & .2 & \\
\hline & $>3$ & 1.25 & 0.77 & 2.03 & .4 & & 1.37 & 0.77 & 2.43 & .3 & \\
\hline \multirow[t]{3}{*}{ Paralysis } & 0 to 1 & 0.52 & 0.11 & 2.49 & .4 & .7 & 0.33 & 0.07 & 1.59 & .2 & .4 \\
\hline & 2 to 3 & 0.83 & 0.45 & 1.52 & .5 & & 0.97 & 0.46 & 2.04 & .9 & \\
\hline & $>3$ & 1.25 & 0.40 & 3.85 & .7 & & 1.14 & 0.31 & 4.15 & .8 & \\
\hline \multirow[t]{3}{*}{ Any reoperation } & 0 to 1 & 1.26 & 0.94 & 1.69 & .1 & .3 & 1.35 & 0.96 & 1.89 & .08 & .1 \\
\hline & 2 to 3 & 1.02 & 0.86 & 1.22 & .8 & & 1.02 & 0.83 & 1.24 & .9 & \\
\hline & $>3$ & 1.33 & 0.90 & 1.97 & .1 & & 1.64 & 1.00 & 2.69 & .05 & \\
\hline \multirow{3}{*}{$\begin{array}{l}\text { Reoperation-bleeding/ } \\
\text { tamponade }\end{array}$} & 0 to 1 & 1.27 & 0.92 & 1.75 & .1 & .06 & 1.30 & 0.90 & 1.88 & .2 & .02 \\
\hline & 2 to 3 & 0.86 & 0.70 & 1.04 & .1 & & 0.83 & 0.66 & 1.03 & .09 & \\
\hline & $>3$ & 1.27 & 0.84 & 1.92 & .3 & & 1.60 & 0.93 & 2.75 & .09 & \\
\hline \multirow[t]{3}{*}{ Reoperation-graft occlusion } & 0 to 1 & 1.97 & 0.86 & 4.48 & .1 & .8 & 1.66 & 0.64 & 4.30 & .3 & .7 \\
\hline & 2 to 3 & 2.30 & 1.26 & 4.19 & .007 & & 2.46 & 1.22 & 4.96 & .01 & \\
\hline & $>3$ & 3.50 & 0.64 & 19.11 & .1 & & 3.64 & 0.41 & 32.60 & .2 & \\
\hline \multirow[t]{3}{*}{ New RF (no previous RF) } & 0 to 1 & 1.23 & 0.83 & 1.81 & .3 & .3 & 1.48 & 0.94 & 2.34 & .09 & .4 \\
\hline & 2 to 3 & 1.08 & 0.90 & 1.30 & .4 & & 1.16 & 0.93 & 1.44 & .2 & \\
\hline & $>3$ & 1.59 & 0.95 & 2.67 & .08 & & 1.66 & 0.89 & 3.11 & .1 & \\
\hline \multirow[t]{3}{*}{ Prolonged ventilation } & 0 to 1 & 1.09 & 0.90 & 1.33 & .4 & .5 & 1.08 & 0.87 & 1.35 & .5 & .5 \\
\hline & 2 to 3 & 0.98 & 0.88 & 1.09 & .7 & & 0.98 & 0.87 & 1.10 & .7 & \\
\hline & $>3$ & 0.92 & 0.71 & 1.20 & .6 & & 0.88 & 0.66 & 1.16 & .4 & \\
\hline \multirow[t]{3}{*}{ Pneumonia } & 0 to 1 & 1.03 & 0.73 & 1.45 & .9 & .8 & 1.21 & 0.81 & 1.80 & .4 & .3 \\
\hline & 2 to 3 & 0.98 & 0.80 & 1.19 & .8 & & 0.94 & 0.76 & 1.16 & .5 & \\
\hline & $>3$ & 1.15 & 0.75 & 1.78 & .5 & & 1.30 & 0.77 & 2.17 & .3 & \\
\hline \multirow[t]{3}{*}{ Pacemaker/ICD } & 0 to 1 & 1.22 & 0.77 & 1.95 & .4 & .6 & 0.96 & 0.58 & 1.59 & .9 & .5 \\
\hline & 2 to 3 & 1.15 & 0.91 & 1.46 & .2 & & 1.21 & 0.91 & 1.59 & .2 & \\
\hline & $>3$ & 0.83 & 0.43 & 1.58 & .6 & & 0.86 & 0.43 & 1.73 & .7 & \\
\hline \multirow[t]{3}{*}{ Readmission: $30 \mathrm{~d}$} & 0 to 1 & 0.95 & 0.83 & 1.10 & .5 & .9 & 0.92 & 0.78 & 1.08 & .3 & .8 \\
\hline & 2 to 3 & 0.97 & 0.90 & 1.06 & .5 & & 0.96 & 0.88 & 1.06 & .4 & \\
\hline & $>3$ & 1.00 & 0.83 & 1.21 & 1.0 & & 0.98 & 0.80 & 1.22 & .9 & \\
\hline \multirow[t]{3}{*}{ LOS $<6 \mathrm{~d}$} & 0 to 1 & 0.97 & 0.92 & 1.03 & .3 & .5 & 0.98 & 0.92 & 1.03 & .4 & .8 \\
\hline & 2 to 3 & 1.00 & 0.95 & 1.05 & 1.0 & & 0.99 & 0.95 & 1.04 & .8 & \\
\hline & $>3$ & 0.98 & 0.91 & 1.07 & .7 & & 0.99 & 0.90 & 1.07 & .8 & \\
\hline
\end{tabular}

$P O C$, Partial occluding clamp; $S C$, single clamp; $R R$, relative risk; $C I$, confidence interval; $T I A$, transient ischemic attack; $R F$, renal failure; $I C D$, implantable cardioverterdefibrillator; $L O S$, length of stay. 